\title{
ART IN THE PROCESS OF INTEGRATING THE DON COSSACK HOST TO THE RUSSIAN STATE
}

\author{
Tatyana S. Rudichenko \\ Rostov State S. Rachmaninov Conservatory, Rostov-on-Don, Russian Federation
}

\begin{abstract}
Introduction. Studying culture and art in the formation of the Cossacks, designing its estate status is carried out in the perspective of current ideas about cultural policy contributing to more complete systemic reconstruction of the process. The novelty consists in showing the interaction of artistic and traditional household culture, the transformation of the latter. The purpose and objectives were analyzing the role of art in integrating the Cossacks into the Russian state, identifying the direction of changes in the culture; historical periodization of perception and adaptation of new art forms; establishing the specificity of the selected periods and the results achieved. Methods and materials. Research methods include the historical one, which allows considering changes in culture based on facts of social history, and cultural one, which gives approaches to studying regulation of the integration process in accordance with the principles of cultural policy. The source base consists of published official documents (letters, laws, decrees) containing reliable information, and art criticism, historical and ethnographic literature, which describes specific phenomena of culture and art. Analysis. The supreme power used effective and relevant for a particular historical period institutions and resources: religion and church $\left(17^{\text {th }} \mathrm{c}\right.$.); service in the army and military education system $\left(18^{\text {th }} \mathrm{c}\right.$.); reforming of social organization (incorporation into the estate structure of the state) and the control system of the Army (separation of the military and civilian system of administration) $\left(19^{\text {th }} \mathrm{c}\right.$.). Results. By creating infrastructure, developing church and secular education, the government promoted systemic renewal of culture and Cossacks' digestion of its forms that were perceived in Russia and Europe as close, identical and related (architecture, painting, choral singing and orchestra music, drama and musical theater). At the early stage of integration into the Russian state, contact forms and democratic nature of the cultural interaction process prevailed. Cultural expansion of the $18^{\text {th }}-19^{\text {th }}$ centuries had a systemic nature and was determined by purposeful influence of the institutions (church, army, school and social elite) that contributed to renewal of culture according to the Western European model.
\end{abstract}

Key words: Don Cossack Host, Don Cossacks, culture Europeanization, art, integration into the Russian state.

Citation. Rudichenko T.S. Art in the Process of Integrating the Don Cossack Host to the Russian State. Vestnik Volgogradskogo gosudarstvennogo universiteta. Seriya 4. Istoriya. Regionovedenie. Mezhdunarodnye otnosheniya [Science Journal of Volgograd State University. History. Area Studies. International Relations], 2019, vol. 24, no. 4, pp. 215-223. (in Russian). DOI: https://doi.org/10.15688/jvolsu4.2019.4.18

Дата поступления статьи: 01.04.2019

ББК 63.3(2/7) Дата принятия статьи: 18.06.2019

\section{ИСКУССТВО В ПРОЦЕССЕ ИНТЕГРАЦИИ ВОЙСКА ДОНСКОГО В РОССИЙСКОЕ ГОСУДАРСТВО}

\section{Татьяна Семеновна Рудиченко}

Ростовская государственная консерватория им. С.В. Рахманинова, г. Ростов на Дону, Российская Федерация

Аннотация. Введение. Изучение роли культуры и искусства в становлении казачества, оформлении его сословного статуса осуществляется в ракурсе актуальных представлений о культурной политике, способствующих более полному системному воссозданию процесса; новизна заключается в показе взаимодействия художественной и традиционной бытовой культуры, трансформации последней. Цель и задачи состоят в анализе роли искусства в интеграции казачества в Российское государство, выявлении направленности 
изменений в культуре; исторической периодизации восприятия и адаптации новых форм искусства; установлении специфики выделенных периодов и достигнутых результатов. Meтоды: исторический, позволяющий рассматривать изменения в культуре в опоре на факты социальной истории, и культурологический, дающий подходы к изучению регулирования интеграционного процесса в соответствии с принципами культурной политики. Источниковую базу составили опубликованные официальные документы (грамоты, законы, указы), содержащие достоверные сведения, искусствоведческая, историческая и этнографическая литература, в которой описываются конкретные явления культуры и искусства. Анализ. Верховная власть использовала эффективные и актуальные для конкретного исторического периода институты и ресурсы: религию и церковь (XVII в.); службу в армии и войсковую систему образования (XVIII в.); социальную организацию (встраивание в сословную структуру государства) и систему управления (разделение военной и гражданской системы правления) (XIX в.). Результаты. Создавая инфраструктуру, развивая церковное и светское образование, власть способствовала системному обновлению культуры, усвоению казаками тех ее форм, которые воспринимались в России и Европе как близкие, идентичные и родственные (архитектура, живопись, хоровое пение и оркестровая музыка, драматический и музыкальный театр). На раннем этапе интеграции в Российское государство преобладали контактные формы и демократичный характер процесса культурного взаимодействия. Культурная экспансия XVIII-XIX вв. имела системный характер и определялась целенаправленным влиянием институтов (церковь, армия, икола и социальная элита), способствовавших обновлению культуры по западноевропейскому образцу.

Ключевые слова: Войско Донское, донское казачество, европеизация культуры, искусство, интеграция в Российское государство.

Цитирование. Рудиченко Т. С. Искусство в процессе интеграции Войска Донского в Российское государство // Вестник Волгоградского государственного университета. Серия 4, История. Регионоведение. Международные отношения. - 2019. - Т. 24, № 4. - C. 215-223. - DOI: https://doi.org/10.15688/jvolsu4.2019.4.18

Введение. Культура казачества в научных исследованиях и обыденных представлениях, как правило, отождествляется с традиционной, а ее роль абсолютизируется. Это в известном смысле оправданно, так как именно в ее формах проявляется специфика и идентифицирующие свойства. Значение же такой составляющей культуры, как художественное творчество - в его преимущественно эстетической направленности, недооценено. Изучение культуры и искусства в аспекте становления казачества и обретения статуса в сословной системе Российского государства позволяет рассмотреть проблему в ракурсе современных научных представлений о культурной политике как одной из функций государства. Такой подход актуален, так как представляет процесс в более полном системном виде, а новизна состоит в показе взаимодействия художественной и традиционной бытовой культуры, а также трансформации последней. Целью исследования является оценка роли искусства как одного из факторов интеграции казачества в Российское государство, задачи работы заключаются в выявлении направленности трансформационных процессов в культуре; в исторической периодизации восприятия и адаптации новых форм искусства; в установлении специфики выделенных периодов и достигнутых результатов.

Методы и материалы. Изучение изменяющегося и развивающегося объекта обусловливает применение исторического метода, позволяющего рассматривать его в опоре на факты социальной истории. Культурологический подход позволил применить понятие культурной политики и принципы ее изучения к регулированию государственной властью интеграционного процесса в сфере культуры и искусства.

Источниковую базу исследования составили опубликованные официальные документы (грамоты, указы, законы) [1; 2; 8; 11; 17], содержащие достоверные сведения и факты, искусствоведческая, историческая и этнографическая литература $[3-7 ; 9 ; 10 ; 12-15 ; 16$; 18]. В используемой литературе изучаются и описываются конкретные явления культуры и искусства вне контекста проблематики данной статьи.

Анализ. Политика российских властей в отношении казачества приобрела целенаправленный характер со времени воцарения на династии Романовых и продолжала совершенствоваться до последней четверти XIX в., когда завершаются реформы (1874-1875) и 
интеграция казачества в Российскую империю, а его культура выходит на новый уровень развития.

Искусство в начале XVIII в. в донском казачьем войске развивалось во взаимодействии форм традиционной бытовой и инновационной художественной культуры. Процесс этот является системным свойством культуры, имеет перманентный характер и поддается административному регулированию, включая конструирование, что и происходило в ходе вовлечения казачества в Российское государство.

Государство распространяло свое влияние, используя институты и ресурсы, эффективные и актуальные для каждого конкретного исторического этапа взаимодействия с казаками.

Для XVII в. это было усиление социально-экономического и духовно-религиозного влияния (установление ${ }^{1}$ и регулярная выдача казакам жалованья; устроение религиозноцерковной жизни: обеспечение богослужебными книгами, церковной утварью).

Для XVIII в. - это реформы церковного и военного управления и становление на Дону системы образования (подчинение Воронежской епархии с 1718 г. [8, с. 193-195]; перевод с 1721 г. в распоряжение Военной коллегии и служба казаков в иррегулярных войсках Российской империи [11, с. 367]; открытие учебных заведений).

Для второй половины XVIII и XIX в. реформирование социальной организации самого Войска. До 20-х гг. XVIII в. высшим органом управления и суда был Войсковой круг, решавший военные, церковные и гражданские вопросы, а исполнительную власть представляли выборные атаман, два есаула и дьяк. В 1775 г. учреждается Войсковое гражданское правительство, в ведение которого передано "хозяйственное... распоряжение» [2, № 115-116, с. 205-210], а в 1797 г. при Павле I в Войске Донском восстанавливается «прежний образ правления» [2, № 120, с. 260]. С 1798 г. казачество встраивается в сословную структуру государства: казачьи военные чины приравниваются к чинам Российской армии $[2$, № 1130, с. 420$]$, донская старши́на получает личное дворянство. Меняется система управления Войском: в 1718 г. Петром I впервые были подтверждены права выборного «войскового донского атамана», а с 1723 г. вместо выборного атаман назначается из казаков и с 1735 г. (атаманства Ивана Фролова) именуется наказным [16, с. 401-402]; с М.Г. Хомутова - из высших армейских чинов.

Культурное развитие казаков в XVIXVII вв. стимулировалось походами к Кавказскому побережью Черного моря, в Крым, на Балканы, паломничеством и основанием собственных монастырей (в середине XVII в. их известно уже пять), что способствовало росту влияния религии, усвоению культовых и внекультовых форм христианской культуры.

Духовный опыт казаков отражен в устном и письменном творчестве, обнаруживающем знакомство с переводной античной и средневековой христианской литературой (греческой и славянской балканской). Заимствования сюжетов и типических мест (loci communes) из этого рода источников прослеживаются в эпической песне об Александре Македонском (см.: [7, № 44]), духовном стихе о вавилонском знамении [7, № 26]; эпической песне о стареющем Орле. В устной и письменной форме зафиксированы тексты пародийных повестей «О Фоме и Ерёме» (в виде песни), «О бражнике» и фрагменты апокрифов «Сказание как сотворил Бог Адама», «Беседа трех святителей» и др. [14; 15].

Литературные ассоциации и заимствования выявляются в поэтической «Повести об Азовском взятии и осадном сидении донских казаков»: фольклорно-книжное поэтическое сравнение войск с непроходимым лесом, описание степи в ожидании боя, апокалипсические образы «скончания века», излюбленные в библейской поэзии символы Орла и Льва («Слово о полку Игореве», «Задонщина» и другие повести).

Западное (европейское) влияние на казаков шло как со стороны «украинных земель», входивших в состав Польши и Литвы, так и со стороны Москвы. Связи донцов с запорожцами и монастырями на польско-литовских землях - крупными центрами просвещения способствовали распространению грамотности, обновленных форм искусства богослужебного канона (иконописи, барочной церковной архитектуры, многоголосного - партесно- 
го - пения) и светского искусства (парсуны, инструментальной музыки, танцев и др.).

Известно, сколь большое значение придавал изменению по европейскому образцу богослужения и официальных торжеств Петр I. В период его правления создается значительное число песнопений панегирического характера («Стихи победительные», «Службы благодарственные», канты и виваты, иногда объединяемые в последования, «Виватная сиюта», концерты, исполняемые во время триумфальных шествий) [10]. Развивается весь арсенал средств барочной культуры, способствовавших прославлению побед русского оружия (эмблемы, фейерверки, триумфальные арки, театрализованные шествия воинов, пленников и пр.). Начиная со взятия Азова в 1696 г. участвовавшие в триумфальных входах войск казаки приобщались к новым формам официальной праздничной культуры.

K 30-м гг. XVIII в. относится самое раннее документальное свидетельство об умении петь по нотам [12, с. 197] ${ }^{2}$. Сохранились документы об обучении священниками казачьих детей грамоте и пению уже в начале XVIII века [3, с. 147].

Для подготовки казачьего духовенства Елизавета Петровна, ориентируясь на опыт «братских школ» и коллегиумов, открывает в Черкасске в 1746 г. Войсковую латинскую семинарию [1, № 413, с. 414-417], что, впрочем, не нашло должного понимания у войсковой администрации и казачьей верхушки. Поскольку в семинарии в числе прочих дисциплин преподавали латинский язык и поэзию, ее деятельность воспринималась как распространение на Дону «латинской ереси». Просуществовав 10 лет, «при удобном случае» она была закрыта [5, с. 105].

C 20-х гг. XVIII в. одним из путей обновления культуры становится служба в Российской армии. После подавления Булавинского восстания (1707-1709) на Дону постоянно находятся ее полки, располагаясь в районах, бывших в эпицентре восстания, а также в окраинных крепостях, знакомя население с такими армейскими видами музыки, как сигнальная и маршевая, полковое хоровое пение, солдатская песня.

Постепенно вовлекаемые в военную службу донские казаки усваивают этот пласт мужской культуры, как и устные исторические рассказы, образцы нового типа силлаботонической поэзии, ее жанры, что способствовало мощному обновлению фольклора казачества. Разумеется, церковь, будучи встроенной в иерархию общества, не исключая и армии, сохраняла свое влияние, проводя его через священников и регентов.

Важным фактором усложнения структуры культуры, давшим толчок трансформационным процессам, стало формирование культуры казачьего дворянства, получение образования, как необходимого условия карьерного роста, и функционирование характерных для сословия форм и видов творчества. Атаман А.И. Иловайский «заботился о насаждении образования» и ходатайствовал о разрешении детям казаков поступать в Московский университет [16, с. 427], что благосклонно было воспринято Г.А. Потемкиным.

Открытое в Черкасске при А.И. Иловайском в 1790 г. начальное народное училище, а c 1793 - главное, готовило учителей и войсковых писарей [16, с. 427]. Учебные планы включали стандартные для того времени дисциплины. Число выпускников училища и основанной в результате его преобразования в 1805 г. гимназии не было значительным, как и продолживших обучение в университетах, поэтому не могло еще оказывать на культуру существенного влияния. Однако именно получившие образование молодые люди, наряду с работавшими в России иностранцами, создают первые исторические и этнографические описания Войска и бытового уклада его обитателей [18]. Роль просвещзения заметно усиливается в 30-70-е гг. XIX в., когда оно в складывается в развитую систему. Однако при достаточном количестве школ и разного профиля училищ неоднократные инициативы открыть высшее учебное заведение не увенчались успехом.

В 1868 г. это удалось сделать лишь в сфере духовно-религиозной. Существование в Новочеркасске Духовной семинарии позволило получать хорошее образование, не покидая родного края. Далеко не все выпускники семинарии, как полагалось, становились священниками, но пополняли ряды образованных людей. Делом их жизни становилась литература, изобразительное искусство, наука (в их 
числе донские писатели Р.П. Кумов, А.С. Серафимович (Попов), К.А. Тренёв, собиратель и исследователь казачьего фольклора А.М. Листопадов, его товарищ по экспедициям начала 1900-х гг., окончивший позднее географический факультет Московского университета, С.Я. Арефин и многие другие).

Донские атаманы, старшины и рядовые казаки, еще сохранявшие в своем сознании память о былом партнерстве с Русью и Россией, в течение всего XVIII в. ориентировались на жизнь столицы. Тенденция европеизации в это время находит свое выражение в архитектуре, изобразительном, певческом искусстве, инструментальном исполнительстве и новых формах времяпрепровождения.

Казачья столица и окружные станицы приобретают черты российских городов. Донские помещики заказывают столичным архитекторам проекты усадебных ансамблей с дворцами, домовыми церквами и другими сооружениями. Также поступает и администрация Войска, приглашая для осуществления различных градостроительных планов проектировщиков и строителей-инженеров, нередко иностранцев (как А.И. Ригельман и Ф.П. де Воллан).

Небольшие деревянные пирамидальные храмы, реализующие характерную для моделей традиционной культуры казаков идею «вложенного пространства», при личном содействии Петра I и Елизаветы Петровны заменялись каменными барочными, нередко с классическими элементами (ордером). Почти сформировавшееся к середине XVIII в. подворье атаманов Ефремовых включало настоящий дворец, возведенный в классическом стиле по типу петербургских и московских, - домо́вую церковь во имя иконы Донской Божьей матери, прообразом которой считают трехкупольную Воздвиженскую церковь Киево-Печерской лавры (1700), дарителем которой был атаман Данила Ефремов [6, с. 56-57].

Иконостасы черкасских храмов выполнялись московскими мастерами (иконостас Воскресенского Войскового собора - Егором Ивановым Греком в 1749 г.) [6, с. 67], а домовой церкви Ефремова - греческими и итальянскими мастерами $[6, \text { с. } 58]^{3}$.

Складывающийся слой донской аристократии, ориентировавшейся на русское дворянство, нуждался в самоутверждении. Одним из способов, который был унаследован от эпохи Средневековья, было создание новой генеалогии, запечатленной на портретах и придававшей кланам выдвиженцев солидность и легитимность. На атаманском подворье размещается картинная галерея, для которой в середине - второй половине XVIII в. создаются портреты донских атаманов, их жен, а также императриц и членов царской семьи (чем подтверждалась верность престолу). Жалование подобных портретов донским атаманам (как, например, в 1749 г. Даниле Ефремову портрета императрицы Елизаветы с бриллиантами) становилось своеобразным символическим скреплением договора между властью и казаками.

На рубеже XVIII-XIX вв. в Черкасске успешно трудятся талантливые художники, в том числе донские уроженцы: А. Жданов (принятый в Академию художеств), Е. Копылов (выпускник этой Академии), И. Арабский. Но портреты атаманов и членов их семей пишут также известные отечественные мастеpa: А.П. Антропов и В.А. Тропинин. Авторы статьи о донском парадном портрете И. Гуржиева и М. Соколенко отмечают «стилистическую однородность парсуны XVIII века и развитие ее лучших художественных качеств в XIX веке» $[4$, с. 2]. Несколько позднее появляется батальная живопись, увековечившая подвиги в битвах рядовых казаков и их предводителей, создававшая живописную историю казачества, и пейзажная, запечатлевшая неповторимою природу степного края (Н.Н. Дубовской, И.И. Крылов).

Черкасская соборная певческая капелла в 70-е гг. XVIII в. преобразуется в Войсковую, ориентировавшуюся в своей деятельности на петербургскую Придворную певческую капеллу [3, с. 71]. Содержавшаяся на войсковые средства, она выполняла одновременно функции церковного и военно-церемониального хора. В 20-х гг. XIX в. (1826-1827) в г. Таганроге, в резиденции Александра I, была создана и функционировала по 1862 г. Придворная певческая капелла [3, с. 108-109, 125]. В репертуар обоих хоров входил полный круг церковного пения и светские произведения. В Войсковую приглашали в основном казаков, благодаря чему партесное пение (пение по партиям), отличавшееся сочетанием 
тембров мужских голосов, контрастами плотности и громкости звучания, проникало в разные уголки Дона, образуя очаги своеобразного по складу многоголосия, затронув мужскую народно-песенную сферу. Очевидные связи с партесным многоголоси$e м$ обнаруживает сложившийся у казаков протяжный распев.

Влияние украинско-польского многоголосия XVII-XVIII столетий прослеживается в казачьих протяжных песнях не только в стилистике голосовых партий и их наименовании, но и в некоторых приемах барочной композиции, таких как: амплификация (расширение, выражающееся преимущественно в повторении элементов музыкально-поэтического текста), антитетон (противоположение, особенно ярко проявляющееся в контрасте сольного запева и хорового подхвата, противопоставлении партий запевалы и подголоска - «дишканта»), апокопа (усечение, применяемое в виде обрыва слова и его «допевания»), палилогия (в данном случае цепная связь окончаний и начал смежных стихов) и др. Родство в строфике, ритмике и многоголосии, формообразовании с другой разновидностью партесного пения - кантами - обнаруживается в ряде строевых казачьих песен.

C начала XIX в. в среде донского дворянства получает развитие бытовая развлекательная культура, прежде всего бальная. На домашних и официальных $б a-$ лах исполняются соответствующие моде того времени европейские танцы, и звучит инструментальная музыка [13]. В первой трети XIX в. до десятка донских дворян имело оркестры.

Описывая досуг черкасских жителей 1820-х гг., В.Д. Сухоруков упоминает об игpax (в короли и кончики - с платками) [18, c. 75], танцах (под звуки балалайки или «оркестра», «состоявшего из двух скрипок, дудочки, цимбалов и баса») $[18$, с. 76]. Танцевальная культура развивалась в соответствии с модой: от казачка и журавля до барыни, «Как у наших у ворот», хлопушки, которые танцевали в четыре пары «наподобие кадрили, только без вальса» $[18$, с. 76]. Как видим, столичные веяния конца XVIII - начала XIX в. достаточно быстро внедрялись в быт донской столицы.
В 20-е гг. XIX в. в Новочеркасске и Таганроге появляются театры (соответственно в 1825 и 1827 гг.). Существующий на началах антрепризы театр донской столицы долгое время не имел специального помещения, своей труппы и оркестра. Спектакли (драматические и музыкальные) в основном давали приглашаемые труппы из Таганрога и других южных городов, как правило украинских. В соответствии с репертуарной политикой провинциальных театров того времени одна и та же труппа нередко давала драматические и музыкально-драматические представления (водевили и оперетты). Лишь для исполнения оперы требовался высокопрофессиональный состав певцов и оркестрантов, что в реальной практике было не всегда. Особенно многочисленны были развлекательные представления (водевили, дивертисменты).

Постоянный театр открылся в Новочеркасске в 1858 году. В 60-70-е гг. на его сцене шли «Гамлет» Шекспира, «Горе от ума» Грибоедова, «Женитьба» Гоголя, «На всякого мудреца довольно простоты» и «Бедность не порок» Островского. Критики на страницах газет отмечали игру талантливых актеров Н.Х. Рыбакова, М.Ф. Яковлева, М.Т. Иванова-Козельского, Ф.И. Козловского и др. Благодаря усилиям и таланту Н.Н. Синельникова к концу века театр стал одним из лучших в провинции. Ему удавалось сочетать в репертуаре развлекательные и серьезные пьесы, привлечь талантливых актеров - В.Ф. Комиссаржевскую, Н.П. Рощина-Инсарова, А.Н. Медведеву, К.А. Каратыгина [9].

Активно развивается литература, журналистика и краеведение, чему способствовало распространение по подписке столичных журналов и газет, издание с 1839 г. первой донской газеты «Донские войсковые ведомости», в «Неофициальной части» которой (с 1852 г.) публиковались статьи по истории, этнографии, фольклору Дона, содержались анонсы и рецензии на важнейшие художественные события. В связи с переименованием в 1870 г. войсковой территории в область Войска Донского с некоторым опозданием (с 1872 г.) и газета в соответствии с общероссийским требованием изменяет название («Донские областные ведомости»). 
К концу века периодическая печать образовала разветвленную сеть, и между изданиями возникло соперничество за внимание читателей и подписку.

Культура Дона в это время уже в полной мере интегрирована в общероссийскую, что проявилось, в частности, в открытии филиалов некоторых императорских обществ и активном включении донской интеллигенции в деятельность столичных (петербургских и московских $)^{4}$. Художественное творчество охватывает литературу, живопись, архитектуру, театр, хоровое и инструментальное исполнительство. Исключением вплоть до конца XIX в. оставалось лишь композиторское творчество, вследствие того что навыки сочинения одаренные жители Дона получали либо в семинарии, либо в Придворной певческой капелле, присваиваемые по окончании курсов которой разряды не позволяли заниматься таким видом деятельности.

Результаты. Схематично представленный процесс становления и развития культуры и искусства в Войске Донском свидетельствует об ускоренном и целенаправленном изменении актуальных компонентов. Их преобразование по западноевропейскому образцу соответствовало решению общих задач культурного строительства в рамках абсолютистского государства.

На раннем этапе интеграции казачества в Российское государство (XVII в.) преобладают контактные формы культурного взаимодействия, связанные с военными походами, посольствами в Москву, паломничеством. Участие в них в той или иной форме большого числа казаков придавало процессу демократический характер. При таком способе заимствуются лишь отдельные элементы языка искусств или культурные тексты.

Следующий этап культурной экспансии (XVIII-XIX вв.) определяется все более расширявшимся целенаправленным влиянием, осуществлявшимся через иерковь, армию, школу и сформировавшуюся, в том числе усилиями государства, сочиальную элиту. Все упомянутые институты были проводниками русской культуры западноевропейского типа. При таком планомерном воздействии трансформационные процессы приобретают системный характер.
Для развития и функционирования культуры и искусства создается соответствующая инфраструктура, роды и виды искусства образуют систему, характерную для российской и европейской культуры Нового времени.

Отмечены такие тенденции, как освоение и создание собственных национально характерных форм и жанров европейской культуры, активизация просвещения, позволившая воспитать талантливых представителей практически всех видов художественного творчества.

Присущие культуре этого периода секуляризачия, расслоение на городскую и сельскую, а также стилевые направления на Дону проявились в усвоении и адаптации различных видов авторского творчества, иеремониальной и развлекательной форм культуры.

Со второй половины XIX столетия заметна синхронизация с общероссийскими направлениями социального и культурного развития; донские казаки воспринимаются в стране как органическая и во многих отношениях одна из лучших частей русского народа.

\section{ПРИМЕЧАНИЯ}

${ }^{1}$ Михаил Федорович установил в 1618 г. дачу казакам жалованья за службу [17, с. 180].

${ }^{2}$ Состояние певческой грамотности на 1800 1801 гг. рассмотрено А.В. Вальченко [3, с. 28-30].

3 В.И. Кулишов полагает, что и проект ее, возможно, был сделан учениками школы великих итальянцев (Растрелли и Ринальди) [6, с. 58].

${ }^{4}$ Русское географическое общество, Общество любителей естествознания, антропологии и этнографии при Московском университете, Товарищество передвижных художественных выставок и др.

\section{СПИСОК ЛИТЕРАТУРЫ}

1. Акты, относящиеся к истории Войска Донского, собранные генерал-майором А.А. Лишиным / изд. Областным правлением Войска Донского ; под ред. А. А. Карасева, Х. И. Попова. - Т. 2, ч. 2. - Новочеркасск : Тип. А.А. Карасева, 1894. - 506 с.

2. Акты, относящиеся к истории Войска Донского, собранные генерал-майором А.А. Лишиным / изд. Областным правлением Войска Донского ; под ред. А. А. Карасева и Х. И. Попова. - Т. 3. - Новочеркасск : Тип. А.А. Карасева, 1894. -483 с. 
3. Вальченко, А. В. Хоровое искусство на Дону (XVIII - начало XX века) : [исследование : монография] / А. В. Вальченко; под ред. Т. С. Рудиченко. - Ростов н/Д : Изд-во РГК им. С.В. Рахманинова, 2014. $-300 \mathrm{c}$.

4. Донской парадный портрет XVIIXIX вв. : Каталог. Живопись. Графика / сост., вступ. ст. И. П. Гуржиевой, М. Е. Соколенко. - М. : Папирус АРС, журн. «Художник», 1993. - 26 с.

5. Королев, В. Н. Донские казаки XVIIXVIII вв. Походы, кругозор и просвещение / В. Н. Королев // Проблемы источниковедения и отечественной истории : (Памяти А. П. Пронштейна) / отв. ред. И. М. Узнародов. - Ростов н/Д : Изд-во РГУ, 1999. C. $92-112$.

6. Кулишов, В. И. В низовьях Дона / В. И. Кулишов. - М. : Искусство, 1987. - 176 с.

7. Листопадов, А. М. Песни донских казаков : в 5 т. / А. М. Листопадов ; под общ. ред. Г. П. Сердюченко. - Т. 1, ч. 1.-М. : Музгиз, 1949. - 246 с.

8 Материалы, относящиеся к церковной жизни Донского казачества в XVIII веке // Памятная книжка Области войска Донского на 1900 год. Новочеркасск : Обл. ВД стат. ком., 1900. - Отд. 4. C. 194-195.

9. Немиров, Ю. А. Годы, спектакли, роли: Из истории театров Дона / Ю. А. Немиров. - Ростов н/Д : Ростовское книжное издательство, 1984. - 205 с.

10. Памятники русского музыкального искусства. Вып. 2 / сост., публ., исслед. и коммент. Вл. Протопопова. - М. : Музыка, 1973. - 254 с.

11. Полное собрание законов Российской империи, повелением государя Николая Павловича составленное. Первое собрание: с 1649 по 12 декабря 1825 года. В 46 т. Т. 6 : 1720-1722 г. / под ред. М. М. Сперанского. - СПб. : Тип. II отд-ния Собств. Е. И. В. Канцелярии, 1830. -818 с.

12. Рудиченко, Т. С. Донская казачья песня в историческом развитии / Т. С. Рудиченко ; отв. ред. О. А. Пашина. - Ростов н/Д: Изд-во РГК им. С.В. Рахманинова, 2004. -512 с.

13. Рудиченко, Т. С. Европейская танцевальная музыка в быту сельского и городского населения Дона / Т. С. Рудиченко // Старинная музыка сегодня : сб. науч. ст. - Ростов н/Д : Изд-во РГК им. С.В. Рахманинова, 2004. - С. 182-192.

14. Рудиченко, Т. С. Об архаических мотивах в былинном эпосе донских казаков / Т. С. Рудиченко // История и культура народов степного Предкавказья и Северного Кавказа: проблемы межэтнических отношений : сб. науч. ст. / ред.-сост. Т. С. Рудиченко. - Ростов н/Д : Изд-во РГК им. С.В. Рахманинова, 1999. - С. 184-202.

15. Рудиченко, Т. С. Христианская традиция и фольклор донских казаков / Т. С. Рудиченко // Вестник Адыгейского государственного университе- та. Серия «Филология и искусствоведение. - Майкоп : Изд-во АГУ, 2012. - Вып. 2. - С. 365-370.

16. Савельев, Е. П. Древняя история казачества / Е. П.Савельев. - М. : Вече, 2013. - 448 с. (Неведомая Русь).

17. Собрание государственных грамот и договоров, хранящихся в государственной коллегии иностранных дел. Ч. 3. - М. : Тип. Селивановского, 1822. $-556 \mathrm{c}$.

18. Сухоруков, В. Д. Общежитие донских казаков в XVI-XVIII столетиях : Ист. очерк / В. Д. Сухоруков. - Новочеркасск : Ред. газ. «Донская Речь», 1892. $-92 \mathrm{c}$.

\section{REFERENCES}

1. Karasev A.A., Popov Kh.I., eds. Akty, otnosyashchiesya $k$ istorii Voyska Donskogo, sobrannye general-mayorom A.A. Lishinym [Acts Relating to the History of the Don Cossack Host Collected by Major General A.A. Lishin]. Novocherkassk, Typografiya A.A. Karaseva, 1894, vol. 2, part 2. $506 \mathrm{p}$.

2. Karasev A.A., Popov Kh.I., eds. Akty, otnosyashchiesya $k$ istorii Voyska Donskogo, sobrannye general-mayorom A.A. Lishinym [Acts Relating to the History of the Don Cossack Host Collected by Major General A.A. Lishin]. Novocherkassk, Typografiya A.A. Karaseva, 1894, vol. 3. $483 \mathrm{p}$.

3. Valchenko A.V. Khorovoe iskusstvo na Donu (XVIII-nachalo XXveka): [issledovanie: monografiya] [Choral Art on the Don $\left(18^{\text {th }}-\right.$ Early $20^{\text {th }}$ Century)]. Rostovon-Don, Izd-vo RGK im. S.V. Rakhmaninova, 2014. 300 p.

4. Gurzhieva I.P., Sokolenko M.E. Donskoy paradnyy portret XVII-XIX vv.: Katalog. Zhivopis. Grafika [Don Parade Portrait of the $17^{\text {th }}-19^{\text {th }}$ c. Catalog. Painting. Graphics]. Moscow, Papirus ARS, zhurnal «Khudozhnik», 1993.26 p.

5. Korolev V.N. Donskie kazaki XVII-XVIII vv. Pokhody, krugozor i prosveshchenie [Don Cossacks of the $17^{\text {th }}-18^{\text {th }}$ c. Campaigns, Outlook and Education]. Problemy istochnikovedeniya $i$ otechestvennoy istorii: (Pamyati A.P. Pronshteyna) [Problems of Source Studies and National History (In Memory of A.P. Pronshtein]. Rostov-on-Don, Izd-vo RGU, 1999, pp. 92-112.

6. Kulishov V.I. V nizovyakh Dona [In the Lower Reaches of the Don]. Moscow, Isskustvo Publ., $1987.176 \mathrm{p}$.

7. Listopadov A.M. Pesni donskikh kazakov: $v 5 t$. [Songs of the Don Cossacks. In 5 Volumes]. Moscow, Muzgiz Publ., 1949, vol. 1, part 1.246 p.

8. Materialy, otnosyashchiesya $\mathrm{k}$ tserkovnoy zhizni Donskogo kazachestva v XVIII veke [Materials 
Relating to the Church Life of the Don Cossacks in the $18^{\text {th }}$ Century]. Pamyatnaya knizhka Oblasti voyska Donskogo na 1900 god [Memorial Book of the Don Cossack Host Region for 1900]. Novocherkassk, Oblastnoy VD statisticheskiy komitet, 1900, part 4, pp. 194-195.

9. Nemirov Yu.A. Gody, spektakli, roli: Iz istorii teatrov Dona [Years, Performances, Roles. From the History of Don Theaters]. Rostov-on-Don, Rostovskoe knizhnoe izdatelstvo, 1984. 205 p.

10. Pamyatniki russkogo muzykalnogo iskusstva. Vyp. 2 [Monuments of Russian Musical Art. Issue 2]. Moscow, Music Publ., 1973. 254 p.

11. Speransky M.M., ed. Polnoe sobranie zakonov Rossiyskoy imperii, poveleniem gosudarya Nikolaya Pavlovicha sostavlennoe. Pervoe sobranie: s 1649 po 12 dekabrya 1825 goda. V 46 t. T. 6: 1720 $1722 \mathrm{~g}$. [Complete Collection of Laws of the Russian Empire Composed by the Order of Sovereign Nikolay Pavlovich. The First Collection. From 1649 to December 12, 1825. In 46 Volumes. Volume 6. 1720-1722]. Saint Petersburg, Tipografiya II otdeleniya Sobstvennoy E. I. V. Kantselyarii, 1830.818 p.

12. Rudichenko T.S. Donskaya kazachya pesnya $v$ istoricheskom razvitii [Don Cossack Song in Historical Development]. Rostov-on-Don, Izd-vo RGK im. S.V. Rakhmaninova, 2004. 512 p.

13. Rudichenko T.S. Evropeyskaya tantsevalnaya muzyka v bytu selskogo i gorodskogo naseleniya Dona [European Dance Mmusic in Everyday Life of Rural and Urban Population of the Don]. Starinnaya muzyka segodnya: sb. nauch. st. [Ancient Music Today. Collection of Scientific Articles]. Rostov-
on-Don, Izd-vo RGK im. S.V. Rakhmaninova, 2004, pp. 182-192.

14. Rudichenko T.S. Ob arkhaicheskikh motivakh v bylinnom epose donskikh kazakov [On Archaic Motifs in the Epic Epos of Don Cossacks]. Istoriya i kultura narodov stepnogo Predkavkazya i Severnogo Kavkaza: problemy mezhetnicheskikh otnosheniy: sb. nauch. st. [History and Culture of the Peoples of the Ciscaucasia and North Caucasus Steppe. Problems of Inter-Ethnic Relations]. Rostov-on-Don, Izd-vo RGK im. S.V. Rakhmaninova, 1999, pp. 184-202.

15. Rudichenko T.S. Khristianskaya traditsiya i folklor donskikh kazakov [Christian Tradition and Folklore of Don Cossacks]. Vestnik Adygeyskogo gosudarstvennogo universiteta. Seriya «Filologiya $i$ iskusstvovedenie [The Bulletin of the Adyghe State University, The Series "Philology and the Arts"]. Maykop, Izd-vo AGU, 2012, iss. 2, pp. 365-370.

16. Savelyev E.P. Drevnyaya istoriya kazachestva [Ancient History of the Cossacks]. Moscow, Veche Publ., 2013. 448 p. (Nevedomaya Rus [Unknown Rus]).

17. Sobranie gosudarstvennykh gramot $i$ dogovorov, khranyashchikhsya $v$ gosudarstvennoy kollegii inostrannykh del. Ch. 3 [Collection of State Certificates and Treaties Stored in the State Chamber of Foreign Affairs. Part 3]. Moscow, Tipografiya Selivanovskogo, $1822.556 \mathrm{p}$.

18. Sukhorukov V.D. Obshchezhitie donskikh kazakov v XVI-XVIII stoletiyakh. Istoricheskiy ocherk [Community Life of Don Cossacks in the $16^{\text {th }}-$ $18^{\text {th }}$ Centuries. Historical Essay]. Novocherkassk, Redaktsiya gazety «Donskaya Rech», 1892. 92 p.

\section{Information about the Author}

Tatyana S. Rudichenko, Doctor of Arts, Professor, Department of Music History, Head of Folk Music Lab, Rostov State S. Rachmaninov Conservatory, Prosp. Budennovskiy, 23, 344002 Rostov-on-Don, Russian Federation,2922191@aaanet.ru, rostovfolklab@mail.ru, https://orcid.org/0000-0002-0047-6194

\section{Информация об авторе}

Татьяна Семеновна Рудиченко, доктор искусствоведения, профессор кафедры истории музыки, заведующая лабораторией народной музыки, Ростовская государственная консерватория им. С.В. Рахманинова, просп. Буденновский, 23, 344002 г. Ростов на Дону, 2922191@aaanet.ru, rostovfolklab@mail.ru, https://orcid.org/0000-0002-0047-6194 